\title{
Malnutrition in an obese world: Can a dietary intervention improve iron status in pre-school children?
}

\author{
Ellen van der Gaag ${ }^{1,2}$, Kim Grootelaar ${ }^{1}$ and Thalia Hummel $^{3}$ \\ ${ }^{1}$ Hospital Group Twente, Almelo, Netherlands, \\ ${ }^{2}$ University Twente, Enschede, Netherlands and \\ ${ }^{3}$ Medical Spectrum Twente, Enschede, Netherlands
}

\section{Abstract}

Introduction: In previous studies iron deficiency was present in preschool children in the developed world ${ }^{1}$. The objective of this randomized controlled trial was to investigate whether iron deficiency was present in pre-school children and to what extend laboratory values could be improved with a nutrient rich diet.

Material and Methods: A diet consisting of green vegetables, beef, full-fat milk and butter was developed. This diet comes close to the traditional Dutch diet from a century ago. All food products were in age appropriate portions, according to the national guidelines. Children aged one to four years, who were referred to the paediatrician due to recurrent URTI (without immunologic disorders) were allocated to the intervention or the control group. Both groups were given standard care. The intervention group was also given the dietary advise. All parents were asked to note of daily food intake.

Results: No iron deficiency was present in our group of $1-4$ years old. Mean $\mathrm{Hb}$ was $7.3 \mathrm{mmol} / \mathrm{l}$ in both groups. After following the dietary advice for 6 months, the hemoglobulin $(\mathrm{Hb})$ concentration increased in both groups, but a little more in the intervention group $:(0,280 \mathrm{mmol} / \mathrm{l} ; \mathrm{p}<0,001$ in the dietary intervention group and $0,214 \mathrm{mmol} / \mathrm{l}$ in the control group; $\mathrm{p}=0,003)$. MCV values increased in the interventiongroup from 77.9 to $78.8 \mathrm{fl}(\mathrm{p}=0.007)$ whereas a smaller increase was visible in the control group ;78.5 to $78.9 \mathrm{fl}(\mathrm{p}=$ 0.18). Ferritin, a marker for iron status but also a marker for inflammation, decreased non-significantly in both groups. There was a significantly correlation with decreasing CRP levels, therefore indicating a decrease in inflammation and not merely representing iron status. Growth parameters (weight, height or BMI) did not change significantly in both groups.

Discussion and Conclusion: $\mathrm{NoHb}$ deficiency was present in our research population. However, a diet consisting of green vegetables, beef, full-fat milk and butter did improve the iron status in pre-school children. $\mathrm{Hb}$ and $\mathrm{MCV}$ values increased, suggesting some evidence of subclinical iron deficiency in this group.

\section{Conflict of Interest}

There is no conflict of interest

\section{Reference}

1. Akkermans MD, van der Horst-Graat JM, Eussen SR, van Goudoever JB, Brus F (2016) Apr; J Pediatr Gastroenterol Nutr 62(4), 635-42. 